\title{
INVESTIGATION ON TEMPERATURE DISTRIBUTION AND THERMAL BEHAVIOR OF LARGE SPAN STEEL STRUCTURES CONSIDERING SOLAR RADIATION
}

\author{
Hongbo Liu ${ }^{1}$, Zhihua Chen ${ }^{1,2, *}$ and Ting Zhou ${ }^{1}$ \\ ${ }^{1}$ Department of Civil Engineering, Tianjin University, Tianjin, 300072, China \\ ${ }^{2}$ Tianjin Key Laboratory of Civil Engineering Structure \& New Materials, Tianjin University, \\ Tianjin, 300072, China \\ *(Corresponding author: E-mail: zhchen@tju.edu.cn)
}

Received: 23 November 2011; Revised: 10 December 2011; Accepted: 7 February 2012

\begin{abstract}
The temperature change is very large for steel structures under solar radiation, and this temperature change can induce remarkable nodal displacement and member stress. In order to obtain the temperature distribution and thermal behavior of large span steel structures under solar radiation, a numerical simulation method was presented in this paper based on the ASHRAE model. In order to provide insights into temperature distribution and provide data to verify the presented numerical simulation method, ten steel plate specimens with different aspect ratios and orientations were investigated by measuring their temperatures under solar radiation. The parameter values in the numerical simulation model were modified by the tests results. Using the temperature numerical simulation method, the temperature distribution and thermal behavior of a typical steel structure, the lattice shell structures, were studied. The study showed that: 1) the solar radiation had a significant effect on the temperature distribution of steel structures. Considering the solar radiation, the temperature of steel structures is about $20^{\circ} \mathrm{C}$ higher than the corresponding ambient air temperature; 2) the temperature change is similar to sine curve from sunrise to sunset; 4) the solar radiation has a remarkable effect on the member stress, nodal displacement and reaction force.
\end{abstract}

Keywords: large span steel structures, steel plate, temperature, solar radiation, experimental research, numerical method

\section{INTRODUCTION}

Steel structures have been popular in recent years. They have many engineering advantages, such as light weight, fast assembly, large span capability and ease to form various attractive geometrical surfaces. Therefore, steel structures are applied particularly in sport stadiums and gymnasiums, exhibition centers, airport, factory buildings.

In the past decades, most researches were devoted to design approaches and investigation on the structural behavior of steel structures. In the design process of steel structures, the structural behavior under the gravity load, dead load, live load, wind load, thermal load, snow load and earthquake action are analyzed. For large span steel structures, the thermal load has a significant effect on its structural behavior. The thermal load includes two types. The first thermal load is that induced by ambient. The second thermal load is that induced by fire. Some investigations were carried out in the past years to understand the structural behavior of steel structures under both thermal load types [1-4].

The first thermal load for all steel structures was considered uniformly in the past years. However, the thermal load of some special steel structures induced by ambient is more no-uniform and higher than the corresponding ambient air temperature due to the solar radiation. The special steel structures include three types. The first type is the steel structures exposed to solar radiation, such as the steel arches shown in Figure 1. The second type is the steel structures which use glass or ETFE as its roof materials, such as the steel arches shown in Figure 2. The third type is the steel structures which use light steel as its roof materials, such as the steel structure shown in Figure 3. 
For the first and the second type steel structures, the solar radiation can irradiate on the steel surface directly. For the third type, the temperature of the steel roof above steel structures is very high because the solar radiation can irradiate on its surface directly, and the distance between the steel structure member and the steel roof is very small. Therefore, the temperature of steel structures was similar to the above light steel roof. Therefore, the solar radiation can induce higher and more no-uniform thermal load for the above three types steel structures.

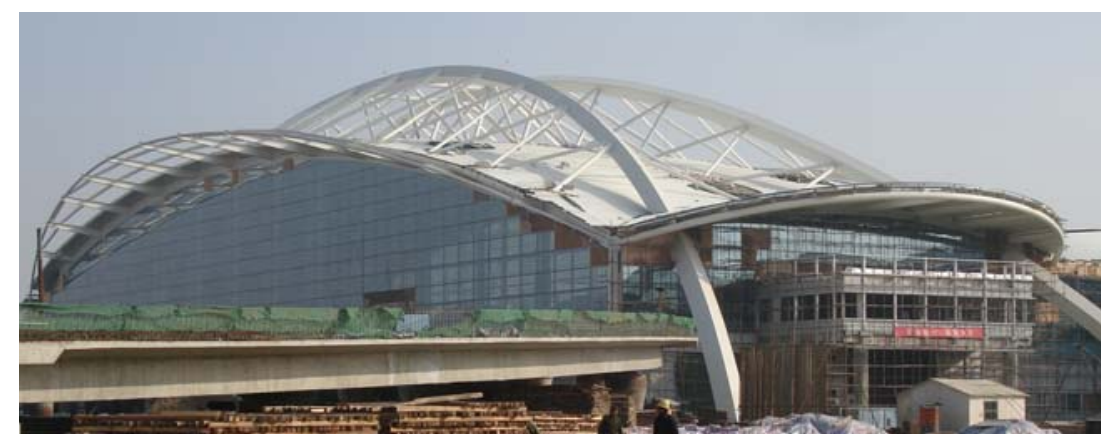

Figure 1. The Steel Arches Exposed to Solar Radiation

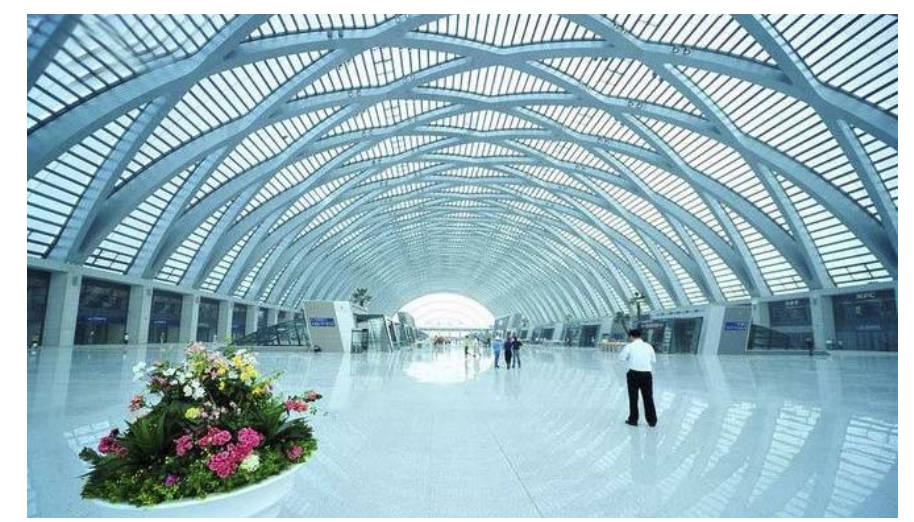

Figure 2. The Steel Arches which use Glass as its Roof

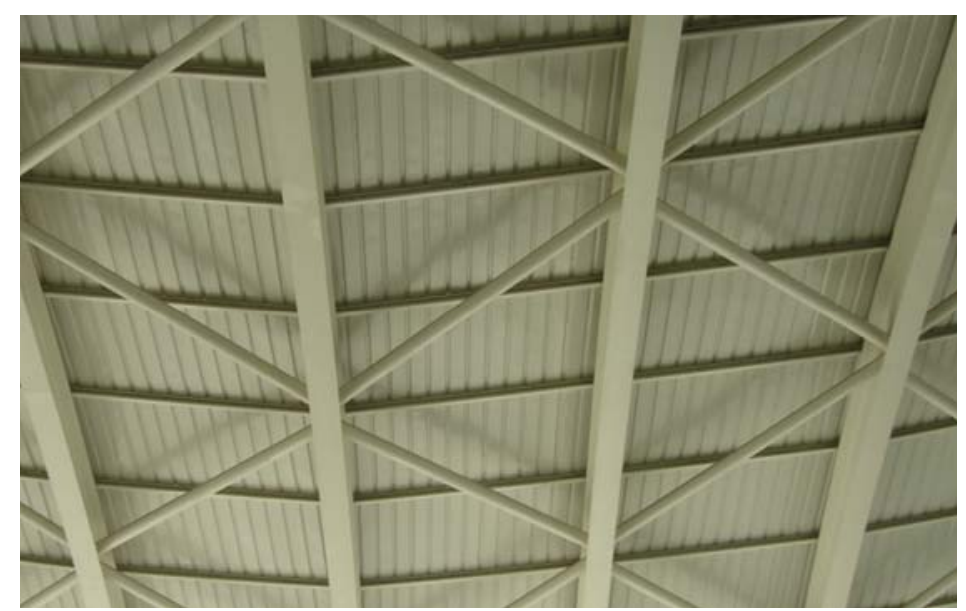

Figure 3. The Steel Structures which use Light Steel as its Roof

For large-span steel spatial structures, thermal load caused by solar radiation may lead some members to ultimate state [5-10]. However, a precise numerical simulation method for the temperature distribution under solar radiation is scarcely mentioned in the published papers. Therefore, the thermal load is difficult to determine in the design process of steel structures. This limitation motivates this study on the numerical simulation method of temperature distribution of steel structures under solar radiation. 


\section{NUMERICAL SIMULATIONS METHOD}

In 1950s, many researchers had already begun to evaluate the temperature distribution of pavements [11-12], bridges [13-15] and dams [16] considering the solar radiation. In these studies, the one-dimensional or two-dimensional heat conductivity model was adopted in the numerical simulation. However, the temperature distribution of the spatial steel structures cannot be predicted using these numerical methods under solar radiation because of its three-dimension spatial property. In this paper, a three-dimensional transient thermal FE model was developed for the analysis on the temperature distribution of large span steel structures under solar radiation based ASHRAE model in ANSYS software.

\subsection{Boundary Condition}

For any steel members exposed to solar radiation, the heat flow acting on its surface includes convection heat, solar radiation and long wave radiation among ground, sky and steel surface. Therefore, the temperature boundary condition for the steel members exposed to solar radiation is defined as:

$\left.\lambda \frac{\partial T}{\partial n}\right|_{\Gamma}=h\left[T_{a}(t)-T\right]+q_{S}(t)+q_{L}(t)$

Where $h$ is heat convection coefficient $\left(w / \mathrm{m}^{2}{ }^{0} \mathrm{C}\right)$; $T_{a}$ is ambient air temperature; $q_{s}$ is solar radiation $\left(\mathrm{w} / \mathrm{m}^{2}\right) ; q_{l}$ is long wave radiation $\left(\mathrm{w} / \mathrm{m}^{2}\right) ; \lambda$ is thermal conductivity $\left(\mathrm{w} / \mathrm{m}^{2}{ }^{0} \mathrm{C}\right)$. The thermal properties of steels were acquired from the corresponding codes as listed in Table 1.

Table 1. Thermal Properties of Steel

\begin{tabular}{|c|c|c|c|}
\hline properties & $\begin{array}{l}\text { density } \\
\mathrm{kg} / \mathrm{m}^{3}\end{array}$ & $\begin{array}{l}\text { Heat conduction coefficient } \\
\qquad \mathrm{J} /\left(\mathrm{m} \cdot \mathrm{s} \cdot{ }^{0} \mathrm{C}\right)\end{array}$ & $\begin{array}{l}\text { Specific heat } \\
\mathrm{J} /\left(\mathrm{kg} \cdot{ }^{0} \mathrm{C}\right)\end{array}$ \\
\hline value & 7850 & 56 & 480 \\
\hline
\end{tabular}

The heat convection coefficient can calculated using following equation presented by Yazdanian and Klems [17]:

$$
h=\sqrt{\left[C_{t}(\Delta T)^{1 / 3}\right]^{2}+\left[a V_{0}^{b}\right]^{2}}
$$

Where $C_{t}$ is the turbulent natural convection constant; $\Delta T$ is the temperature difference between the exterior surface and the ambient air; $a, b$ is the constants; $V_{0}$ is the wind speed at standard conditions.

\subsection{Solar Radiation}

The ASHRAE clear-sky model was adopted in this study to calculate the solar radiation striking the surface of steel members. In this model, the total global solar radiation is assumed to be the sum of direct radiation, diffuse radiation, and the solar radiation reflected from the surrounding surface. At the earth's surface on a clear day, the value of solar radiation is defined as [16] 
$G_{N D}=\frac{A}{\exp (B / \sin \beta)} C_{N}$

Where $G_{N D}=$ normal direct radiation, $W / \mathrm{m}^{2} ; A=$ apparent solar radiation at air mass equal to zero, $W / m^{2} ; B=$ atmospheric extinction coefficient; $\beta=$ solar altitude as it shown in Figure 4; $C_{N}=$ clearness number.

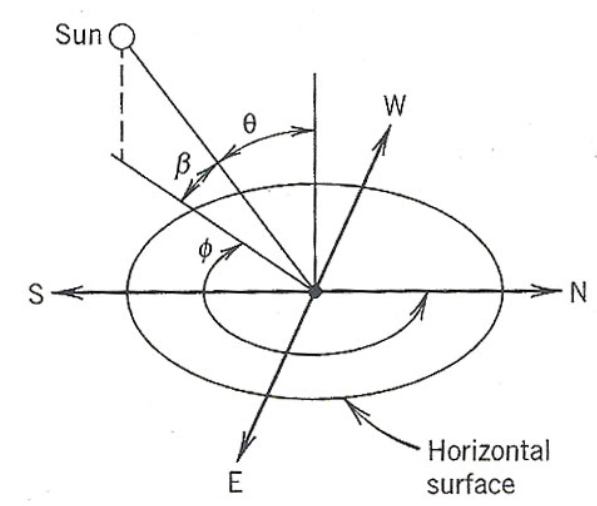

Figure 4. The Solar Altitude Angle $\beta$ and Azimuth Angle $\phi$

On a surface of arbitrary orientation, the direct radiation, corrected for clearness, is [16]:

$G_{D}=G_{N D} \max (\cos \theta, 0)$

Where $\theta$ is the angle of incidence between the sun's rays and the normal to the surface as shown in Figure 4. Note that if $\theta$ is less than zero, there is no direct radiation incident on the surface-it is in the shade. The angle $\theta$ can be calculated by following equations[16]:

$\left\{\begin{array}{l}\cos \theta=\cos \beta \cos \gamma \sin \alpha+\sin \beta \cos \alpha \quad \text { for a tilt surface } \\ \cos \theta=\cos \beta \cos \gamma \quad \text { for a vertical surface } \\ \cos \theta=\sin \beta \quad \text { for a horizontal surface }\end{array}\right.$

$\gamma=|\phi-\psi|$

Where $\gamma$ is surface solar azimuth as it shown in Figure 5; $\alpha$ is tilt angle as it shown in Figure 5; $\phi$ is solar azimuth as it shown in Figure 5; $\psi$ is surface azimuth as it shown in Figure 5.

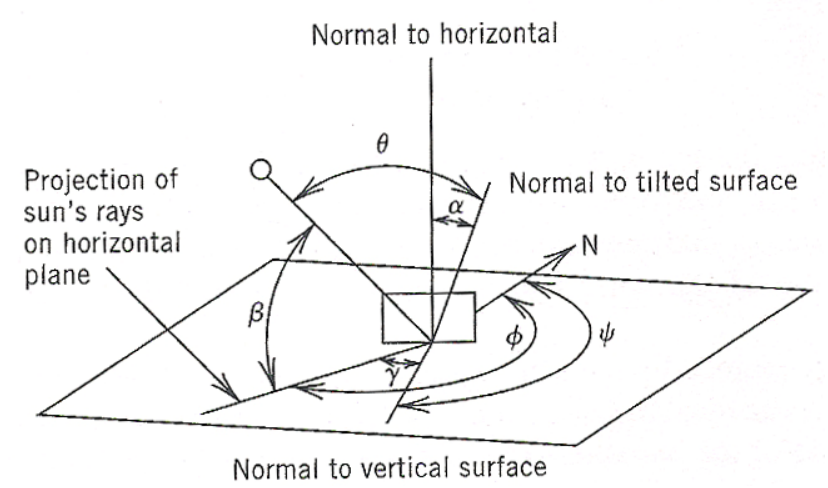

Figure 5. Surface Solar Azimuth $\gamma$, Surface Azimuth $\psi$ and Angle of Tilt $\alpha$ for an Arbitrary Tilted Surface 
The diffuse radiation [16] on a non-horizontal surface is given as follows

$G_{d}=C G_{N D} F_{w s}$

Where $C$ is the ratio of diffuse irradiation on a surface to direct normal radiation; $F_{w s}$ the angle factor between the surface and the sky, and it can be evaluated by $F_{w s}=(1+\cos \alpha) / 2$.

Then, for vertical surface, the diffuse sky radiation [16] is given by:

$$
\begin{aligned}
& G_{d \theta}=\frac{G_{d V}}{G_{d H}} C G_{N D} \\
& \frac{G_{d V}}{G_{d H}}=\left\{\begin{array}{lr}
0.55+0.437 \cos \theta+0.313 \cos ^{2} \theta & \theta>-0.2 \\
0.45 & \text { otherwise }
\end{array}\right.
\end{aligned}
$$

In determining the total rate at which radiation strikes a non-horizontal surface at any time, one must also consider the energy reflected from the ground or surroundings onto the surface. Assuming the ground and surroundings diffusely reflect, the reflected radiation[16] incident on the surface is:

$$
G_{R}=\left(G_{D}+G_{d \theta}\right) \rho_{g} F_{w g}
$$

Where: $G_{R}=$ rate at which energy is reflected onto the surface, $W / m^{2} ; \rho_{g}=$ reflectance of ground or horizontal surface; $F_{w g}=$ configuration or angle factor from surface wall to ground, defined as the fraction of the radiation leaving the surface of interest that strikes the horizontal surface or ground directly. For a surface at a tile angle $\alpha$ to the horizontal: $F_{w g}=(1-\cos \alpha) / 2$.

To summarize, the total solar radiation incident on a non-vertical surface would be found by adding the individual components: direct component, sky diffuse and reflected component:

$$
q_{s}=\varepsilon\left(G_{D}+G_{d}+G_{R}\right)=\varepsilon\left[\max (\cos \theta, 0)+C F_{w s}+\rho_{g} F_{w g}(\sin \beta+C)\right] G_{N D}
$$

Similarly, the total solar radiation incident on a vertical surface would be found by adding the individual components: direct component, sky diffuse and reflected component:

$$
q_{s}=\varepsilon\left(G_{D}+G_{d}+G_{R}\right)=\varepsilon\left[\max (\cos \theta, 0)+\frac{G d V}{G_{d H}} C+\rho_{g} F_{w g}(\sin \beta+C)\right] G_{N D}
$$

Where $\varepsilon$ is the solar absorption coefficient. The solar radiation absorption is affected by its color and smoothness of steel plates. 0.6 was adopted in this study based on the test data.

The parameters $\mathrm{A}, \mathrm{B}$, and $\mathrm{C}$ in the above equations should be determined based on the characteristics of solar radiation at the experiment site. Unfortunately, this information is not yet available. To overcome this problem, the following expressions of parameters $\mathrm{A}, \mathrm{B}$, and $\mathrm{C}$ for Beijing were adopted [18]. The parameters A, B, and C are given as $1326.54 \mathrm{~W} / \mathrm{m}^{2}, 0.404$, and 0.181 on $22^{\text {th }}$ July, 2010. 
Based on the environmental conditions of the experiment site, the parameter for the ASHRAE clear sky model was chosen as $c_{N}=1.0$.

The ground radiation reflectance is affected by its color and smoothness. The value of ground radiation reflectance of bituminous surface is 0.15 based on test data.

\subsection{Long Wave Radiation}

The long wave radiation on the surface of steel plates can be expressed by Stefan-Boltzmann equation [6]:

$q_{l}=\varepsilon_{f} \sigma\left(F_{w g}\left(T_{g}^{4}-T^{4}\right)+F_{w s}\left(T_{s k y}^{4}-T^{4}\right)\right)$

Where $\varepsilon_{f}$ is the ratio of the radiation emitted by a surface; $\sigma$ is Stefan-Boltzmann constant $=5.67 \times 10^{-8} \mathrm{~W} /\left(\mathrm{m}^{2} \cdot \mathrm{K}^{4}\right) ; T_{\text {sky }}$ is the effective temperature of sky, usually calculated by $T_{a}-6 ; T_{g}$ is the ground temperature.

The ambient temperature is a critical parameter affecting the steel temperature, because the convection heat transfer between steel surface and air is determined by the ambient temperature and the long wave radiation irradiating on steel surface. In this paper, the air temperature data for the experiment site were used as shown in Figure 6 and Figure 7.

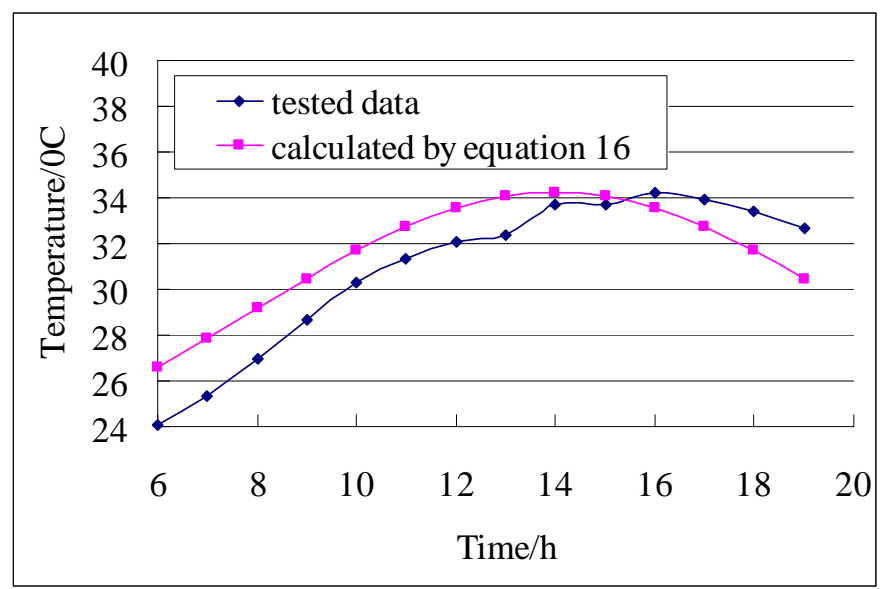

Figure 6. Air Temperature on $22^{\text {th }}$ July on Test Site

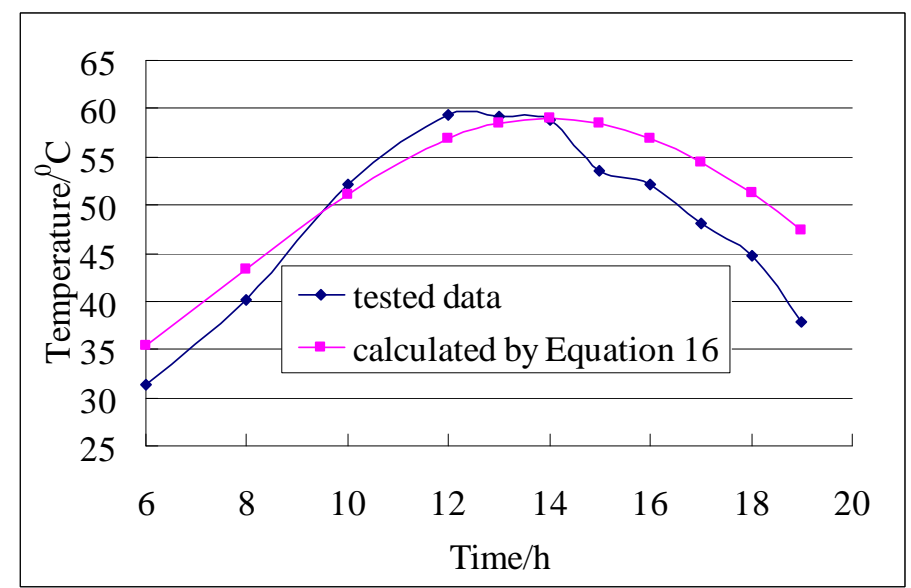

Figure 7. Ground Temperatures on $22^{\text {th }}$ July on Test Site 
If the temperature data is not available in some case, the following equation can be used to define the temperature daily variation:

$T_{a}(t)=T_{a v}+T_{a m} \sin \frac{\left(t-t_{0}\right) \pi}{12}$

Where $T_{a v}$ is the daily mean temperature, defined as $T_{a v}=\left(T_{a \max }+T_{a \min }\right) / 2 ; T_{a m}$ is the amplitude, defined as $T_{a m}=\left(T_{a \max }-T_{a \min }\right) / 2 ; T_{a \max }$ and $T_{a \min }$ are the maximal temperature and minimal temperature. $t_{0}$ is the time when the maximal temperature occurs.

Compared with the temperature data measured on the experimental site, the temperature defined by Eq. 17 is consistent with the temperature data. Therefore, the Eq. 17 can be used to determine the temperature daily variation in the case that the temperature cannot be available.

\section{$2.4 \quad$ Detailed Steps}

Except for steel tubes, the members of steel structures can be divided into some steel plates, for example, the box-sectional steel member is comprised of four rectangular steel plates or eight triangle steel plates. Therefore, here a arbitrary triangle steel plate was used to describe the detailed steps of the three-dimensional transient thermal FE in ANSYS:

Step 1: Build FE model using Shell57 element, and the triangular option was adopted.

Step 2: Calculate the geometric parameters of Shell57 referred by the solar radiation and long wave radiation.

Step 3: Calculate the solar radiation using calculation formulae presented in Section 2.2.

Step 4: Calculate the long wave radiation using calculation formulae presented in Section 2.3.

Step 5: Carry out transient thermal analysis at initial time $t$

Step 6: Calculate the long wave radiation at $t+\Delta t$ using calculation formulae presented in Section 2.3.

Step 7: Re-carry out transient thermal analysis; Step 6 through Step 7 are repeated until the time is up to the end time.

\section{TEST VERIFICATION}

\subsection{Experimental Program}

Ten steel plate specimens were tested to provide insights into temperature distribution of steel structures under solar radiation in summer, and provide data to verify the above numerical simulation method. In order to study the effect of cross-section dimensions and orientation on the temperature distribution, these specimens had different cross-section dimensions and orientations from each other. The cross-section dimension and orientation of each specimen is listed in Table 2 as well as shown in Figure 8. 


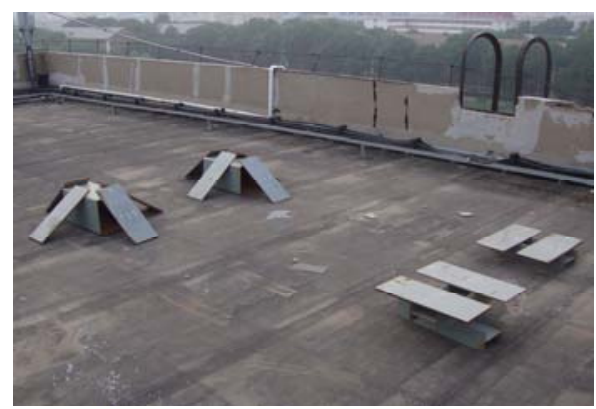

Figure 8. Steel Plate Specimens on Experiment Site

Table 2. The Cross-section Dimension and Orientation of Each Specimens

\begin{tabular}{|c|c|c|c|c|c|}
\hline NUM & PT1 & PT2 & PT3 & PT4 & PT5 \\
\hline cross-section dimension & \multicolumn{5}{|c|}{$500 \times 200 \times 8$} \\
\hline surface azimuth $\psi$ & 0 & 90 & 270 & 180 & 0 \\
\hline Tilt $\alpha$ & 0 & 45 & 45 & 45 & 45 \\
\hline NUM & PT6 & PT7 & PT8 & PT9 & PT10 \\
\hline cross-section dimension & \multicolumn{5}{|c|}{$500 \times 200 \times 14$} \\
\hline surface azimuth $\psi$ & 0 & 90 & 270 & 180 & 0 \\
\hline Tilt $\alpha$ & 0 & 45 & 45 & 45 & 45 \\
\hline
\end{tabular}

In order to obtain the temperature distribution of steel plates, four measured point were designed for ten specimens. An additional measured point was designed for Specimen PT1 and PT6, which was located on the back of measured Point 1. In this test, infra-red temperature meter was used to obtain the temperature of each measured point.

For all the steel plate specimens, the temperature measure points are arranged as Figure 9 shows. The data were obtained at 6:00 am, 8:00 am, 10:00 am, 12:00 am, 13:00 pm, 14:00 pm, 15:00 pm, 16:00 pm, 17:00 pm, 18:00 pm and 19:00 pm on 22th and 23rd July, 2010.

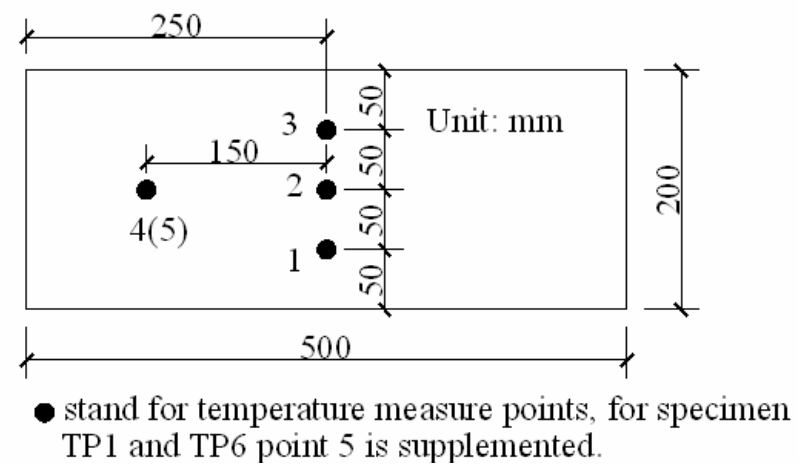

Figure 9. Arrangement of Measure Points

\subsection{Results Analysis}

The temperature-time curves at the maximal temperature and the minimal temperature for each specimen are represented in Figure 10. The temperature-time curves for measure Point 4 and 5 of Specimen PT1 and PT6 are given in Figure 11. The temperature obtained from the transient analysis of each specimen is also shown in Figure 10 and Table 3. 


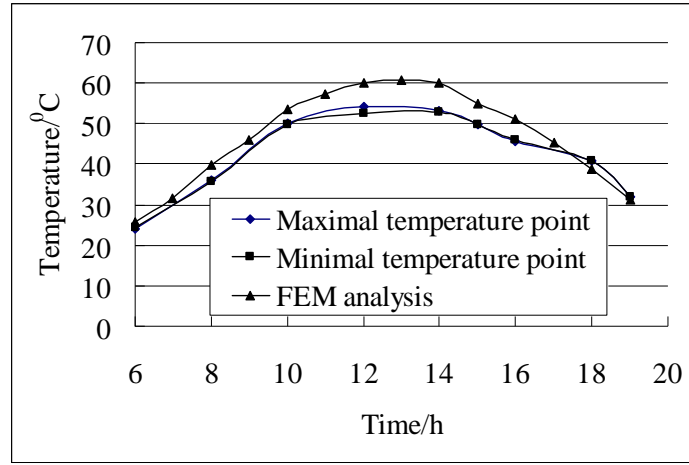

(a) Specimen PT1

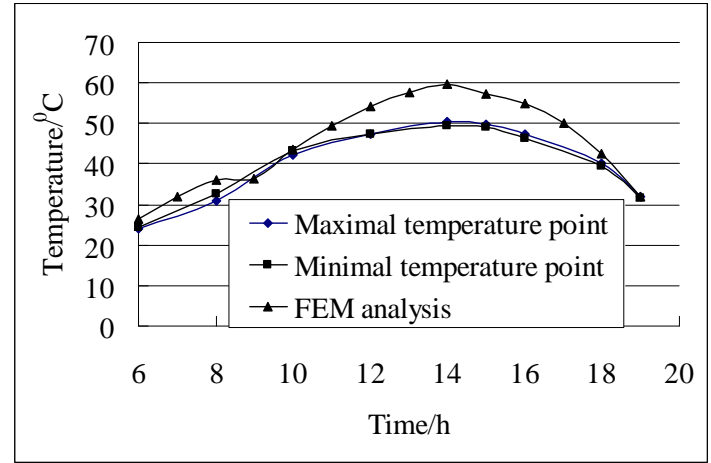

(c) Specimen PT3

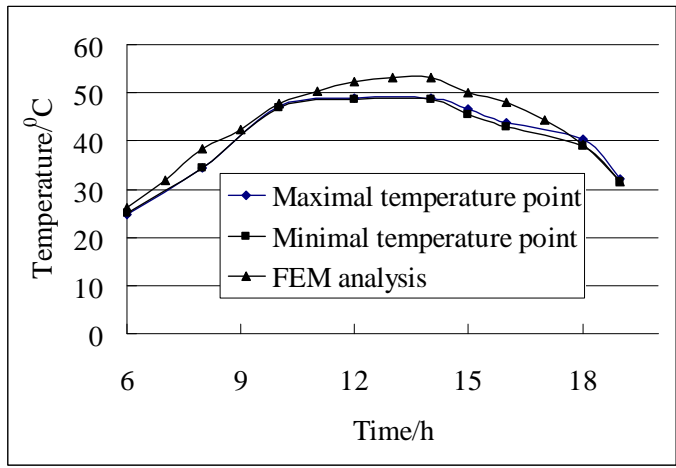

(e) Specimen PT5

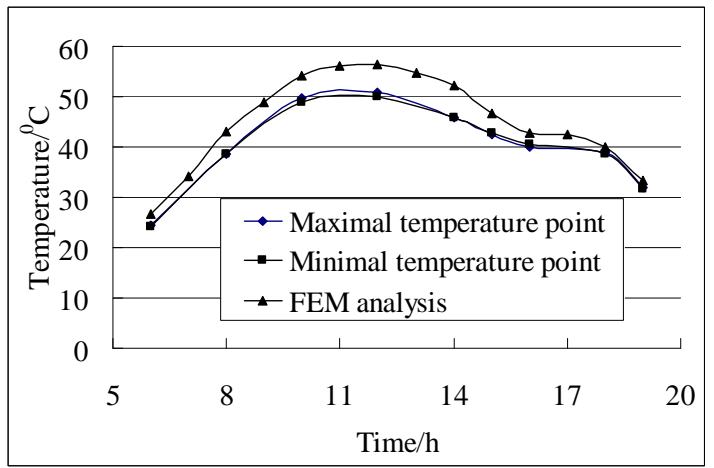

(g) Specimen PT7

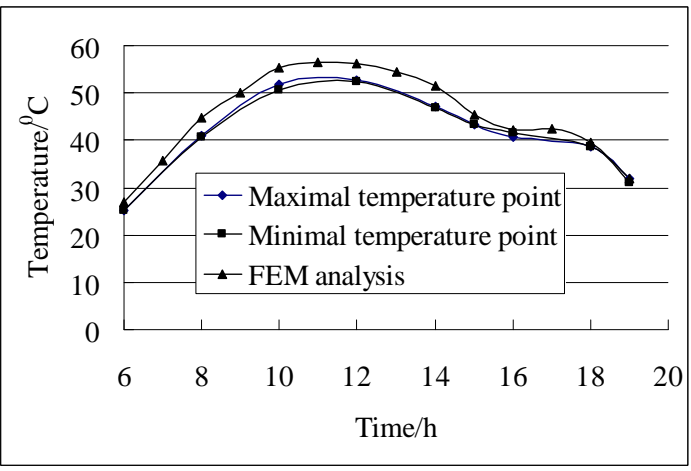

(b) Specimen PT2

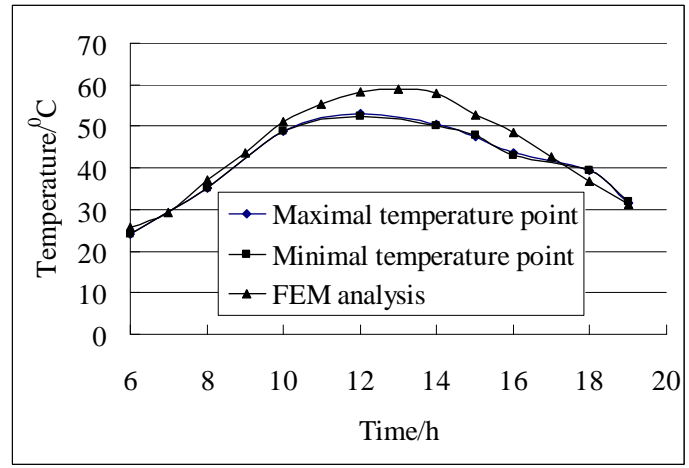

(d) Specimen PT4

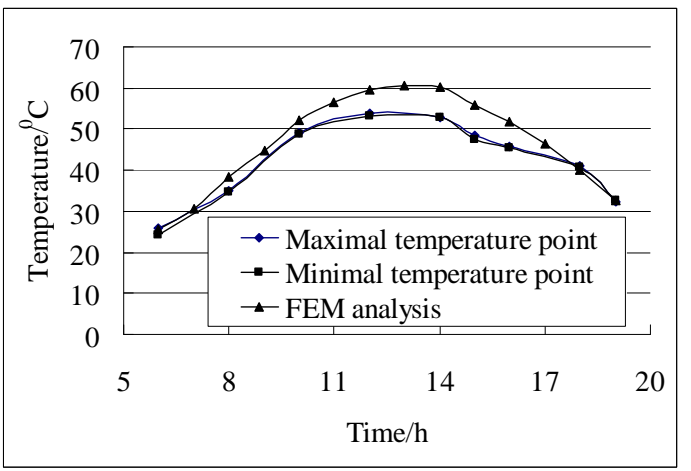

(f) Specimen PT6

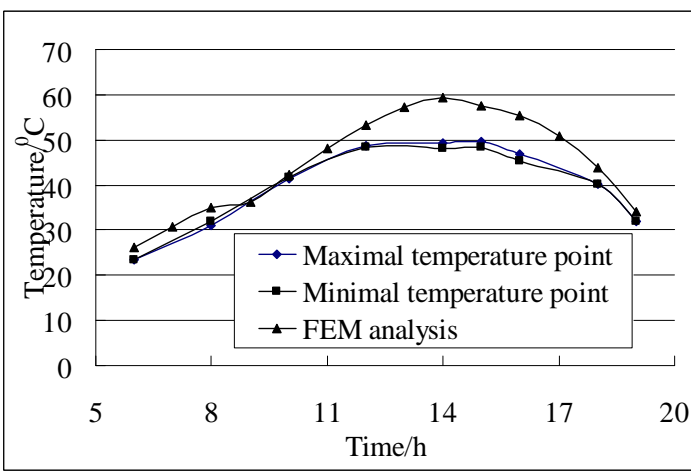

(h) Specimen PT8 


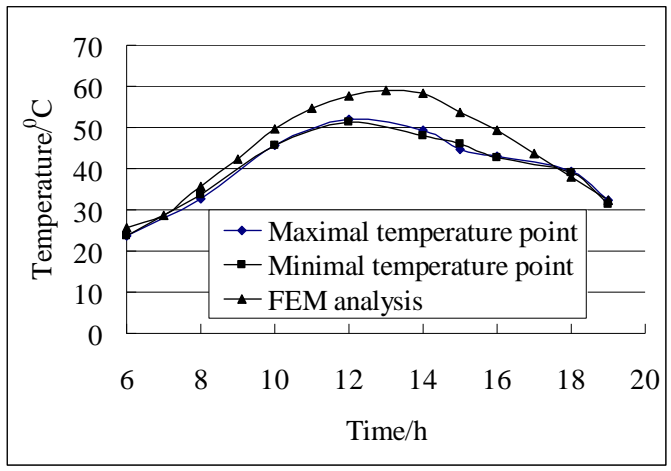

(i) Specimen PT9

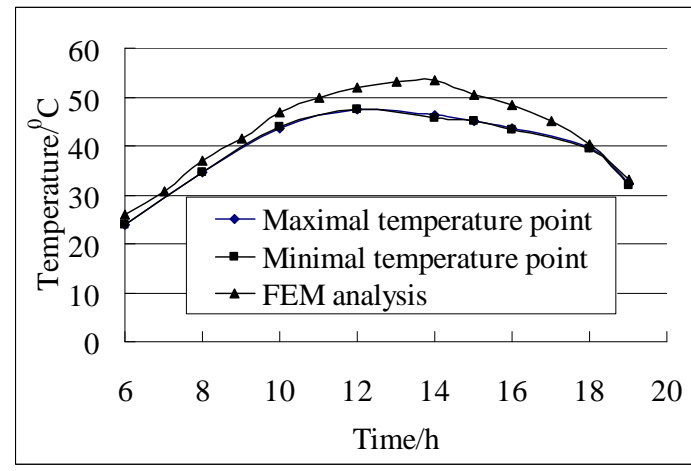

(j) Specimen PT10

Figure 10. Time-temperature Curve of Steel Plate Specimens on 22th July

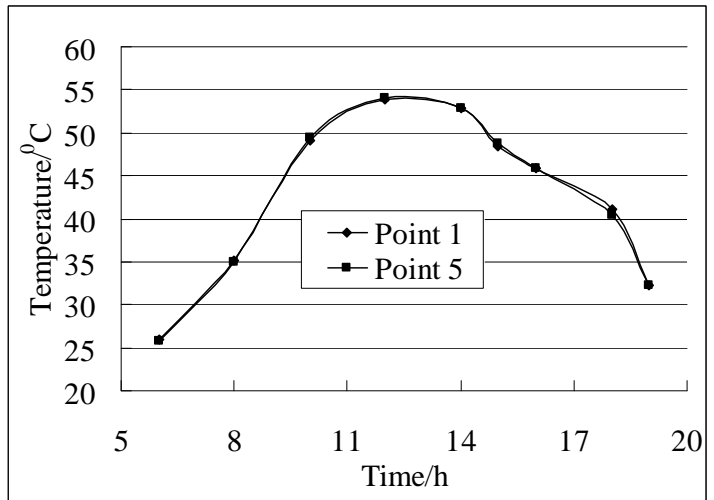

(a) Point temperature on Specimen 1

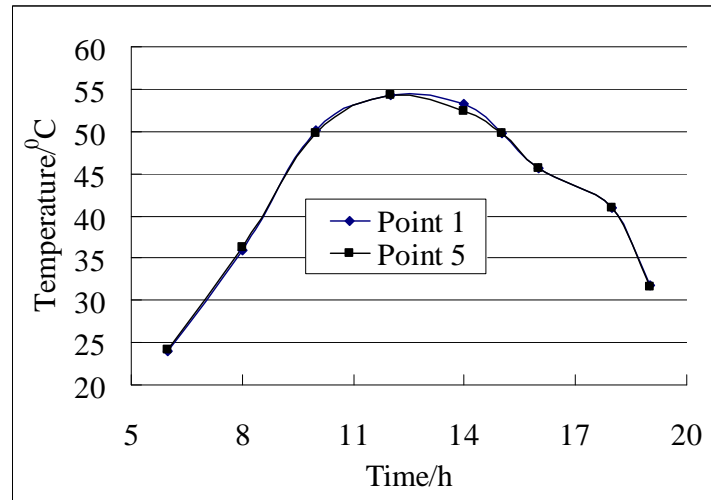

(b) Point temperature on Specimen 6

Figure 11. Time-temperature Curve of Point 1 and Point 5

Table 3. Temperature of 10 Specimens

\begin{tabular}{|c|c|c|c|c|c|}
\hline NUM & PT1 & PT2 & PT3 & PT4 & PT5 \\
\hline Temperature from test on 22 $^{\text {th }}$ July & 54.2 & 51.9 & 50.3 & 53.1 & 49 \\
\hline${\text { Temperature from test on } 23^{\text {th }} \text { July }}^{\text {Nem }}$ & 52.9 & 51.7 & 50.2 & 52.5 & 49.5 \\
\hline Temperature from FEM analysis & 60.77 & 56.39 & 59.7 & 59.02 & 53.29 \\
\hline Error1 & 0.1212 & 0.0865 & 0.1869 & 0.1115 & 0.0876 \\
\hline Error2 & 0.1488 & 0.0907 & 0.1892 & 0.1242 & 0.0766 \\
\hline NUM & PT6 & PT7 & PT8 & PT9 & PT10 \\
\hline Temperature from test on 22 $^{\text {th }}$ July & 53.9 & 50.8 & 49.2 & 52 & 47.5 \\
\hline Temperature from test on 23 $^{\text {th }}$ July & 53.2 & 49.7 & 49.6 & 51 & 48.8 \\
\hline Temperature from FEM analysis $^{\text {Error1 }}$ & 60.64 & 56.31 & 59.35 & 58.87 & 53.38 \\
\hline Error2 & 0.1250 & 0.1085 & 0.2063 & 0.1321 & 0.1238 \\
\hline
\end{tabular}

It is clear that $\mathrm{T}_{\mathrm{FEL}}$ (results obtained from the transient analysis) was generally more than $\mathrm{T}_{\mathrm{T}}$ (results obtained from the tests) with a ratio of 1.0 to 1.2. Therefore, it is clear that the strength $\mathrm{T}_{\mathrm{FEL}}$ was generally consistent with the test results, with a maximum difference of $20.63 \%$. 
Reasons attributing to the discrepancies might be due to variance in the solar radiation model, variance in solar radiation absorption and ground reflectance, precision of infra-red temperature meter, etc. In the test process, the clouds may shelter against solar radiation, which resulted in a decrease of the steel plate specimen's temperature. In order to study the effect of solar radiation decrease on steel plate specimens, the temperature variation of specimen PT7 was obtained by the transient FE analysis under the condition that only solar radiation acted on it with strength of $200 \mathrm{w} / \mathrm{m}^{2}, 400 \mathrm{w} / \mathrm{m}^{2}, 600 \mathrm{w} / \mathrm{m}^{2}$ and $800 \mathrm{w} / \mathrm{m}^{2}$. From Figure 12, it is clear that the temperature increment per min is $0.37{ }^{\circ} \mathrm{C} 、 0.74{ }^{\circ} \mathrm{C} 、 1.11^{\circ} \mathrm{C} 、 1.49{ }^{\circ} \mathrm{C}$ under $200 \mathrm{w} / \mathrm{m}^{2}, 400 \mathrm{w} / \mathrm{m}^{2}, 600 \mathrm{w} / \mathrm{m}^{2}$ and $800 \mathrm{w} / \mathrm{m}^{2}$, respectively.

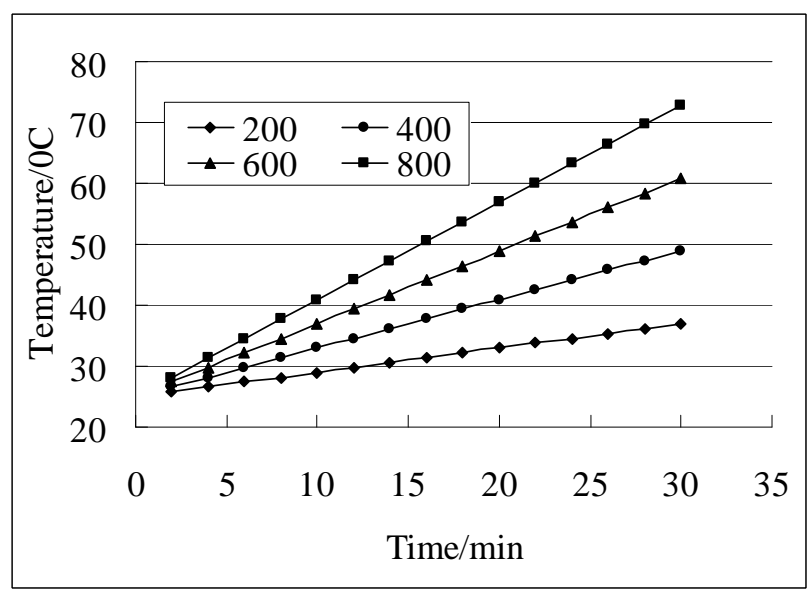

Figure 12. Effect of Solar Radiation on the Temperature of Steel Plate

To sum up the above arguments, the FE simulation results for the steel plate test specimens were generally considered to be precise. Based on the test and numerical results, the following conclusions were drawn on the curves of these figures:

1) For the measure points from Point 1 to Point 4, the temperature-time curves of the maximal temperature point were identical to those of the minimal temperature points. It indicated that the temperature of steel plate was uniformly distributed under solar radiation.

2) The temperature-time curves of all the points were similar to sine curve, and for all the specimens, the maximal temperatures usually occurred at 11:00 am 14:00 pm.

3) The maximal temperature obtained in this experiment was $54.2{ }^{\circ} \mathrm{C}$ with $20^{\circ} \mathrm{C}$ higher than the corresponding ambient air temperature.

4) The temperature-time curves of Measure Point 4 of specimen PT1 and PT6 were identical to those of Measure Point 5. It showed that the temperature in thickness direction was also uniformly distributed.

5) For all the specimens, the maximal temperature was different from each other, and the maximal difference reached $6.7^{\circ} \mathrm{C}$. The temperature distribution of steel plates was affected by their orientation. 


\section{EXAMPLE ANALYSES}

\subsection{The Studied Model}

In order to study the temperature distribution and thermal behavior of steel spatial structures considering the solar radiation, a single-layer lattice shell was designed. This single-layer lattice shell was with a span of $92 \mathrm{~m}$ and a rise of $17 \mathrm{~m}$. steel pipes of $\phi 203 \mathrm{~mm} \times 6 \mathrm{~mm}, \phi 219 \mathrm{~mm} \times 7$ $\mathrm{mm}, \phi 245 \mathrm{~mm} \times 7 \mathrm{~mm}, \phi 273 \mathrm{~mm} \times 8 \mathrm{~mm}, \phi 299 \mathrm{~mm} \times 8 \mathrm{~mm}$ were used as the principal members. The single-layer lattice shell was supported by twenty-four concrete columns. In this study, the boundary conditions were assumed to be simply supported. The studied model was shown in Figure 13.

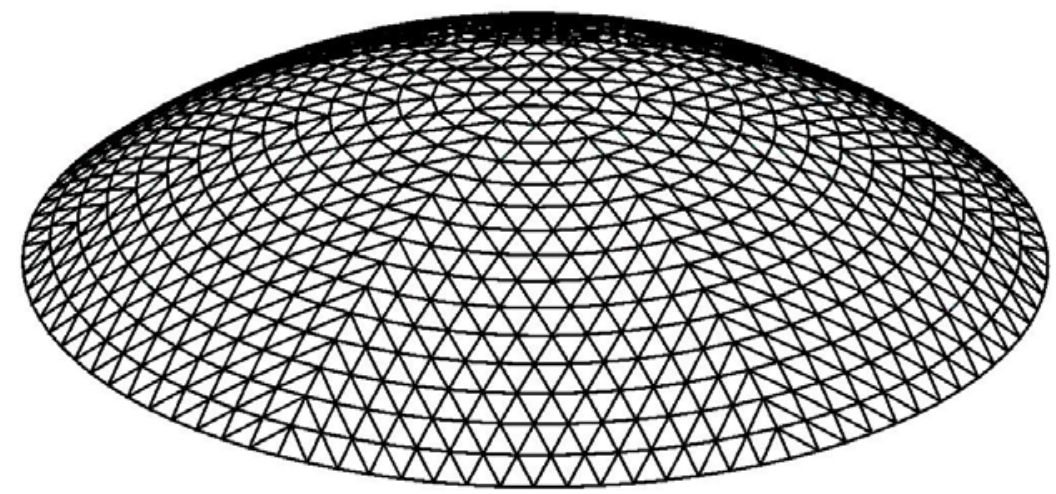

Figure 13. The Studied Model

The light steel roof was used as roof material above the structural members. The temperature of steel members in the single-layer lattice shell was assumed to be similar to the temperature of the above light steel roof.

\subsection{Temperature Distribution of Steel Roof}

Using the numerical simulation method presented in this paper, the temperature distribution of the studied dome model was analyzed. Because the solar radiation on June 21 is the strongest day, June 21 was chosen as the analysis time. The values of all parameters in the numerical simulation model were similar to those of the tested specimens.

The temperature distributions at typical time were shown in Figure 14 to Figure 16. The temperature-time curve of typical node (the center node) is shown in Figure 17. From these figures, it is clear that:

1) The temperature distribution is nearly uniform before sunrise or after sunset.

2) The temperature distribution is very no-uniform under solar radiation, especially around noon. Moreover, the temperature is very high around noon, up to $66^{\circ} \mathrm{C}$ and $31^{\circ} \mathrm{C}$ higher than the corresponding ambient temperature.

3) The temperature-time curve for the steel roof is similar to sine curve. 


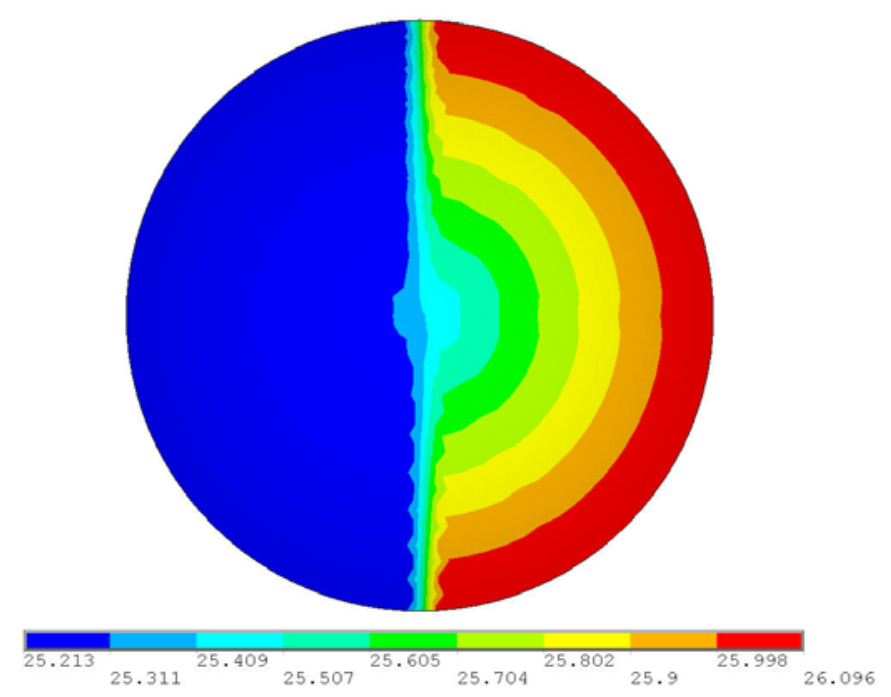

Figure 14. Temperature Distribution of Steel Roof at 6:00 on June 21

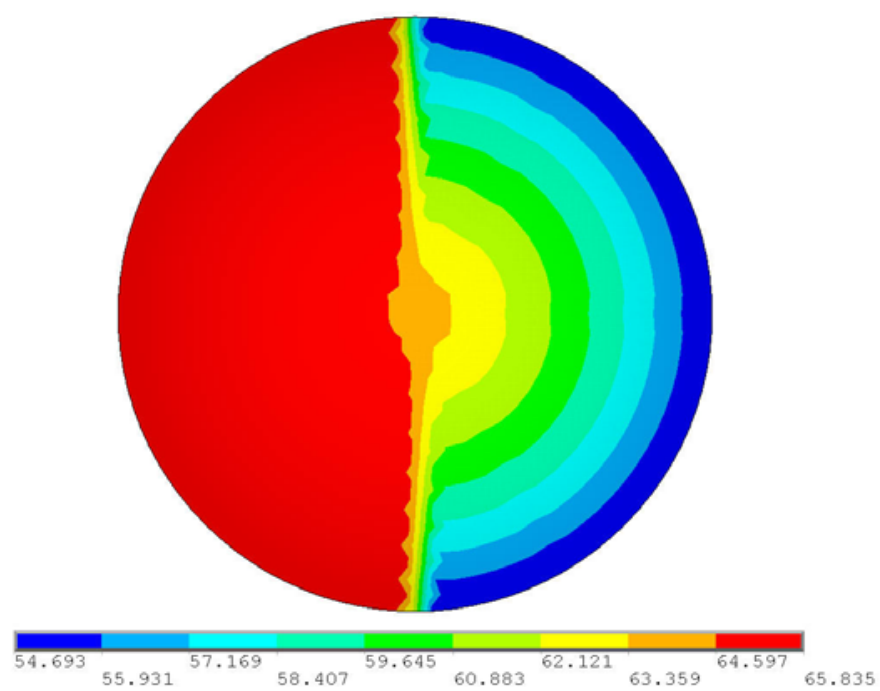

Figure 15. Temperature Distribution of Steel Roof at 14:00 on June 21

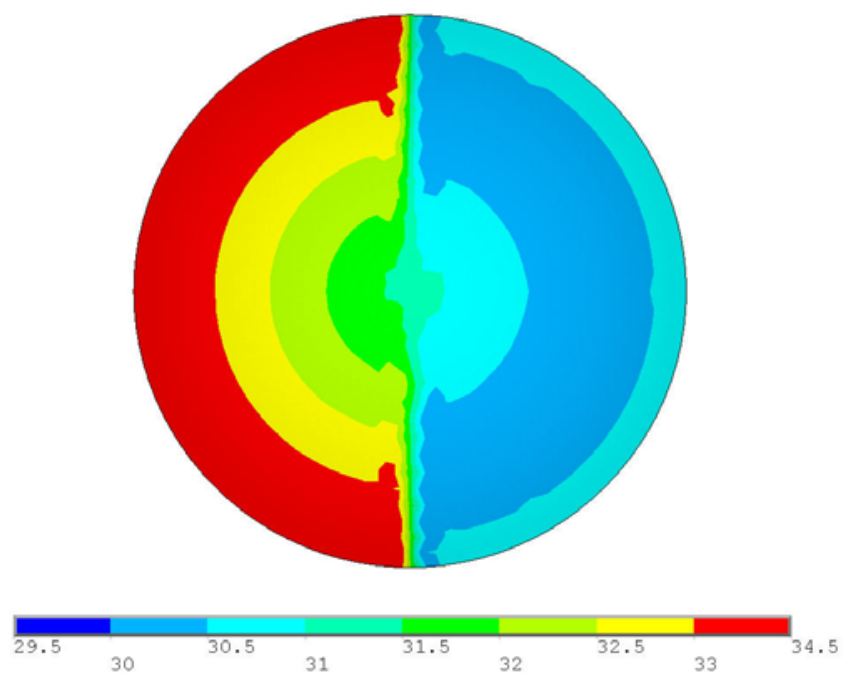

Figure 16. Temperature Distribution of Steel Roof at 19:00 on June 21 


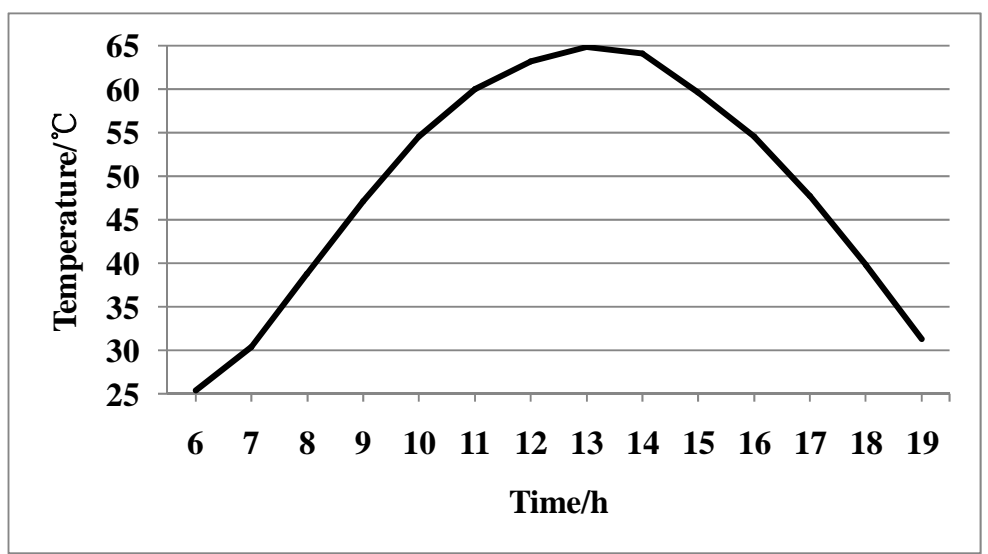

Figure 17. Temperature-time Curve of Typical Node (The Center Node)

\subsection{Thermal Behavior}

Using the temperature field obtained in the Section 4.1, the thermal behavior of the studied dome was analyzed by finite element method. In this paper, ANSYS software was adopted and the BEAM188 was used to simulate the members. The healing temperature for this studied model was assumed to be $10^{\circ} \mathrm{C}$. The maximal nodal displacement $\mathrm{D}$, the maximal member stress $\mathrm{S}$, the maximal reaction force Fx (at radial direction), the maximal reaction force Fy (at circumferential direction) and the maximal reaction force $\mathrm{Fz}$ (at vertical direction) induced by temperature change on June 21 were shown in Figure $18 \sim$ Figure 22. The maximal nodal displacement, the maximal member stress, the maximal reaction force Fx, the maximal reaction force Fy and the maximal reaction force $\mathrm{Fz}$ induced by dead load $\left(1 \mathrm{kN} / \mathrm{m}^{2}\right)$ were $9.5 \mathrm{~mm}, 45.1 \mathrm{Mpa}, 293.8 \mathrm{kN}, 44.9 \mathrm{kN}$ and $249.1 \mathrm{kN}$, respectively.

From these figures, following conclusions can be obtained:

1) The changing curves of D, S, Fx and Fz during a day is similar to the structural temperature changing curve.

2) The variation of $\mathrm{D}, \mathrm{S}, \mathrm{Fx}, \mathrm{Fy}$ and Fz induced by temperature change during a day on June 21 were $37.4 \mathrm{~mm}, 123.3 \mathrm{Mpa}, 176.2 \mathrm{kN}, 156.1 \mathrm{kN}$ and $59.5 \mathrm{kN}$, respectively. They are $393.5 \%, 273.4 \%$, $60.0 \%, 347.6 \%$ and $23.9 \%$ of the corresponding value under dead load. Therefore, it is concluded that the solar radiation has a significant effect on the structural behavior of steel dome structures.

3) Due to the remarkable variation of member stress, it is necessary to study the fatigue behavior of steel dome structure under solar radiation. 


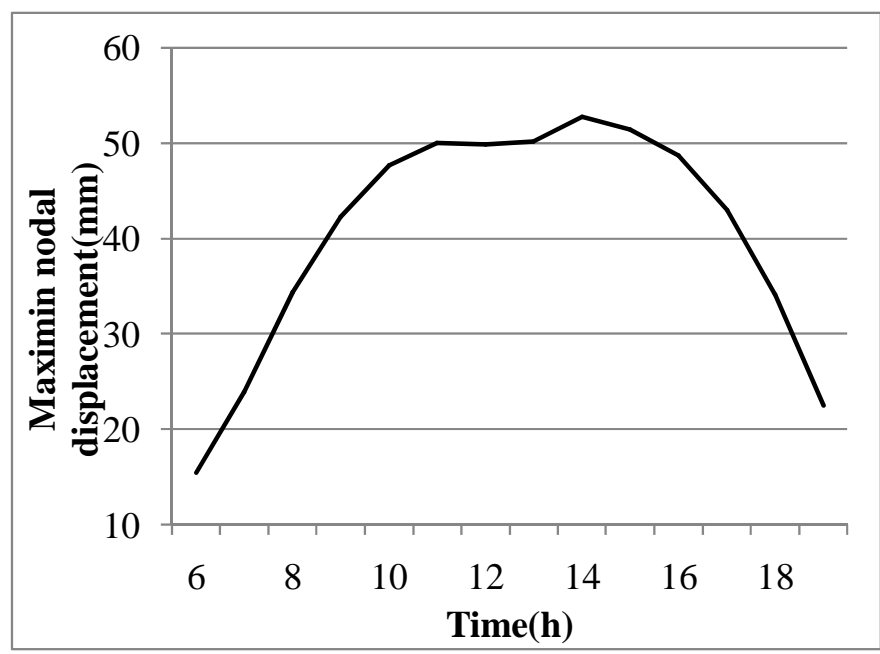

Figure 18. Maximal Nodal Displacement-time Curve Induced by Temperature Change

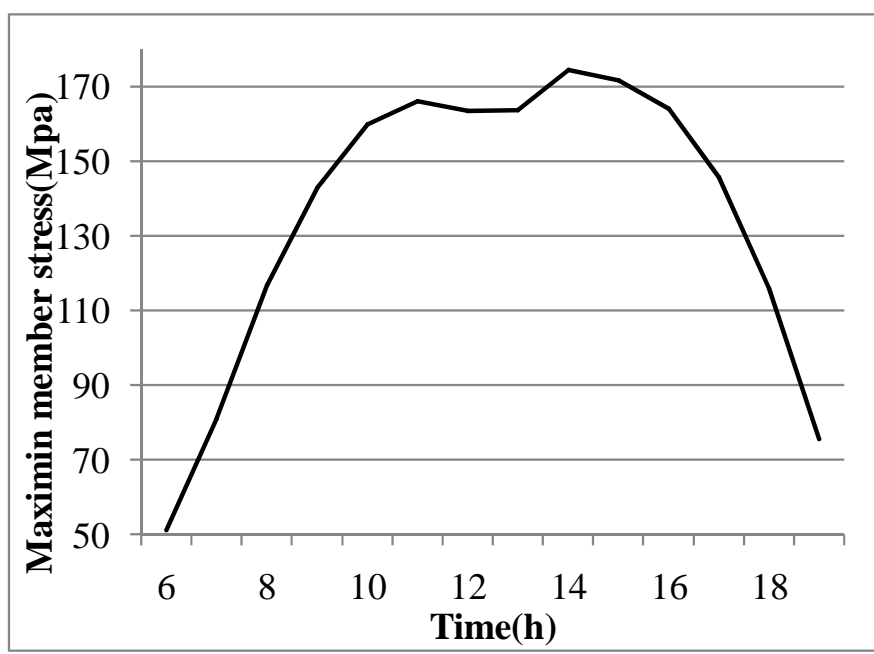

Figure 19. Maximal Member Stress-time Curve Induced by Temperature Change

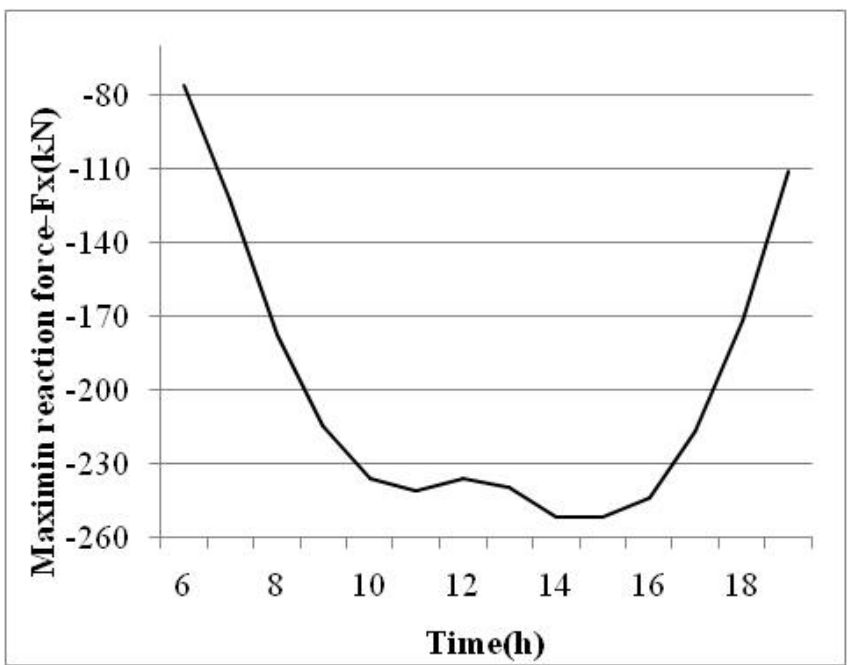

Figure 20. Maximal Reaction Force Fx-time Curve Induced by Temperature Change 


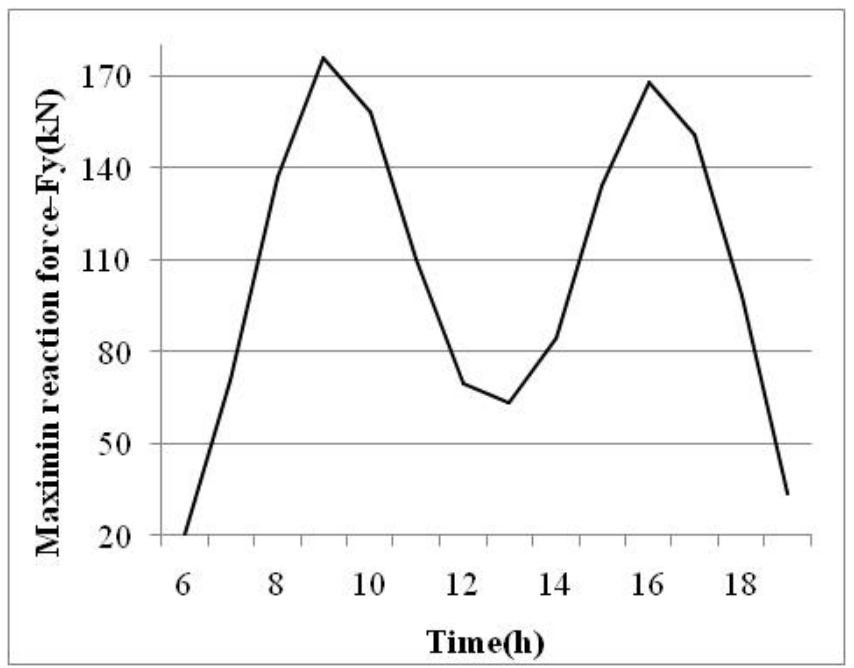

Figure 21. Maximal Reaction Force Fy-time Curve Induced by Temperature Change

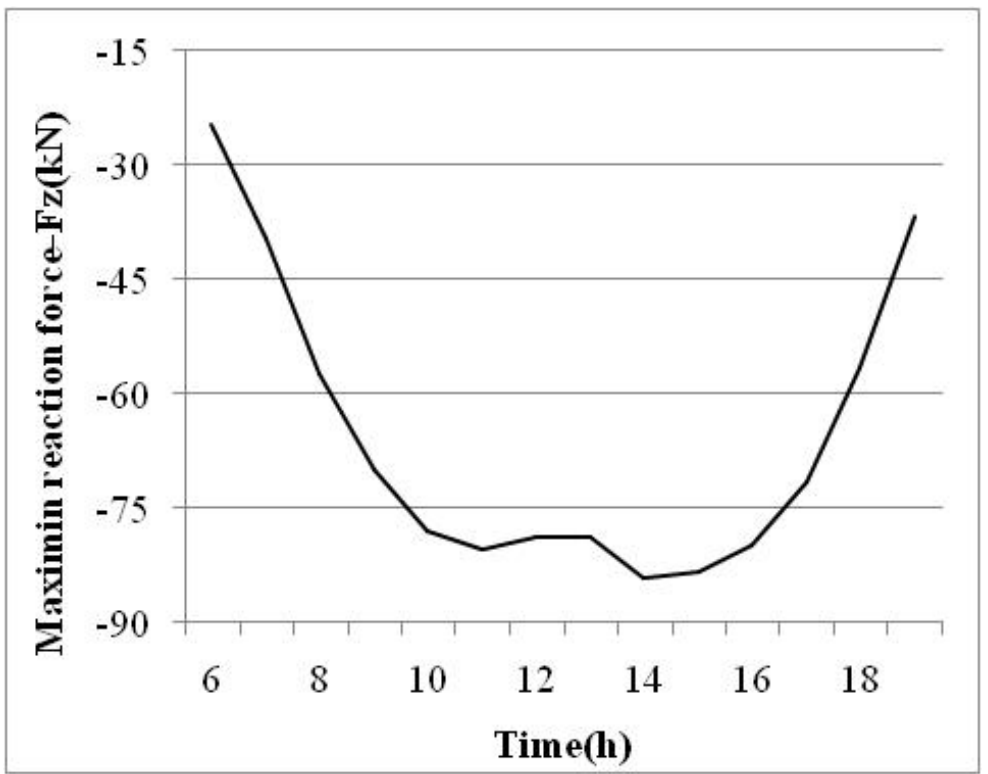

Figure 22. Maximal Reaction Force Fz-time Curve Induced by Temperature Change

\section{CONCLUSIONS}

1) A numerical model, based on a transient thermal FE analysis, was presented for evaluating the thermal performance of steel plates, and its precision is verified by the test data.

2) The daily temperature of ten steel plate specimens with different thickness and orientations were measured on $22^{\text {th }}$ July, 2010. From the test results, the following conclusions were obtained: a) the temperature of steel plates is uniform under solar radiation; b) the temperature-time curve for all point is similar to sine curve; c) The maximal temperature obtained in this experiment is $54.2^{\circ} \mathrm{C}$, and for all specimens, the maximal temperatures usually occurred at 11:00 14:00; d) the temperature in thickness direction is uniform; e) the temperature distribution of steel plates is affected by its orientation.

3) The solar radiation has a remarkable effect on the member stress, nodal displacement and reaction force of steel lattice shell. 


\section{ACKNOWLEDGEMENTS}

This work was supported by the National Natural Science Foundation of China(No. 51208355), China Postdoctoral Science Foundation funded project(No. 2012M510751) and the Independent innovation foundation of Tianjin University(No. 1102, No. 1104).

\section{REFERENCES}

[1] Alinia, M.M. and Kashizadeh, S., "Effect of Flexibility of Substructures upon Thermal Behaviour of Spherical Double Layer Space Truss Domes, Part I: Uniform Thermal Loading”, Journal of Constructional Steel Research, 2006, Vol. 62, No. 4, pp. 359-368.

[2] Alinia, M.M. and Kashizadeh, S., "Effect of Flexibility of Substructures upon Thermal Behaviour of Spherical Double Layer Space Truss Domes, Part II: Gradient \& Partial Loading”, Journal of Constructional Steel Research, 2006, Vol. 62, No. 7, pp. 675-681.

[3] Alinia, M.M. and Kashizadeh, S., "Effects of Support Positioning on the Thermal Behaviour of Double Layer Space Truss Domes”, Journal of Constructional Steel Research, 2007, Vol. 63, No. 3, pp. 375-382.

[4] Yong, D., “A Practical Approach for Fire Risitance Design of Large Space Building Grid Structures [D]”, Shanghai, Tongji University, 2007.

[5] Li, G.Q. and Zhang, C., "Thermal Response to Fire of Uniformly Insulated Steel Members: Background and Verification of the Formulation Recommended by Chinese Code CECS200, Advanced Steel Construction, 2010, Vol. 6, No. 2, pp. 788-802.

[6] Fan, Z., Wang, Z. and Tian, J., "Analysis on Temperature Field and Determination of Temperature upon Healing of Large-span Steel Structure of the National Stadium”, Journal of Building Structures, 2007, Vol. 28, No. 2, pp. 32-40. (in Chinese)

[7] Pei, Y.Z., Bai, Y., Shi, Y.J., Zhu, D. and Wang, Y.Q., "Temperature Distribution in a Long-span Aircraft Hanger [J], Tsinghua Science and Technology, 2008, Vol. 13, No. 2, pp. 184-190.

[8] Xiao, J.C., Xu, H., Liu, J.K. and Ma, K.J., "The Influence of Intense Solar Radiation on Long-span Spatial Steel Structures [J]”, Chinese Journal of Solid Mechanics, 2010, Vol. 31, pp. 275-280.

[9] Wang, Y.Q., Lin, C.C. and Shi, Y.J., "Experimental Study on the Temperature of Steel Members in Sunshine [J]”, Journal of Building Structures, 2010, Supplementary Issue Vol. 1, pp. 140-147.

[10] Jin, X.F., Fan, F. and Shen, S.Z., "Effect of Non-uniform Temperature Field under Sunshine on the Structure Supporting the Reflector of a Large Radio Telescope-FAST [J]", China Civil Engineering Journal, 2008, Vol. 41, No. 11, pp. 71-77.

[11] Brisn, K., Diefenderfer, Imad L. and Al-Qadi Stacey, D. Diefenderfer., "Model to Predict Pavement Temperature Profile: Development and Validation”, Journal of Transportation Engineering, 2006, Vol. 132, No. 2, pp. 162-167.

[12] Andrew, D. Chiasson, Cenk, Yavuzturk and Khaled, Ksaibati, "Linearized Approach for Predicting Thermal Stresses in Asphalt Pavements due to Environmental Conditions", Journal of Materials in Civil Engineering, 2008, Vol. 20, No. 2, pp. 118-127.

[13] Tong, M., Tham, L.G. and Au, F.T.K., ”Numerical Modeling for Temperature Distribution in Steel Bridges”, Computers and Structures, 2001, Vol. 79, No. 6, pp. 583-593.

[14] Kim, S.-H., Cho, K.-I., Won, J.-H. and Kim, J.-H., "A Study on Thermal Behavior of Curved Steel Box Girder Bridges Considering Solar Radiation”, Archives of Civil and Mechanical Engineering, 2009, Vol. 9, No. 3, pp: 59-76. 
[15] Xu, Y.L., Chen, B., Ng, C.L., Wong, K.Y. and Chan, W.Y., "Monitoring Temperature Effect on a Long Suspension Bridge”, Structural Control and Health Monitoring, 2010, Vol. 17, No. 6, pp. 632-653

[16] Jin, F., Chen, Z., Wang, J.T., Yang, J., "Practical Procedure for Predicting Non-uniform Temperature on the Exposed Face of Arch Dams”, Applied Thermal Engineering, 2010, Vol. 30, No. 14-15, pp. 2146-2156.

[17] Faye, C. McQuiston, Jerald, D. Parker and Jeffrey, D. Spitler, "Heating, Ventilating, and Air Conditioning Analysis and Design, USA, John Wiley and Sons, 2005.

[18] Li, J.P. and Song, A.G., "Compare of Clear Day Solar Radiation Model of Beijing and ASHRAE”, Journal of Capital Normal University, 1998, Vol. 19, No. 1, pp. 35-38. (in Chinese) 